\title{
MECB-AODV: A Modified Energy Constrained Based Protocol for Mobile Ad hoc Networks
}

\author{
Akhilesh Tripathi ${ }^{1}$ and Rakesh Kumar ${ }^{2}$ \\ Department of Computer Science \& Engineering, \\ Madan Mohan Malaviya Engineering College, Gorakhpur-273010, INDIA \\ ${ }^{1}$ akhilesh310@yahoo.co.in \\ rrkitregmail. com
}

\begin{abstract}
Mobile ad hoc networks are collection of mobile devices connected by wireless links to perform some computational tasks. This temporary arrangement does not have any infrastructure hence lacking in permanent source of energy. To fulfill this requirement these independent mobile devices are entirely dependent on battery power. The aim of this paper is to design and evaluate the performance of an energy aware routing protocol, called MECB-AODV (Modified Energy Constraint Protocol Based on $A O D V)$ which is derived from $A O D V$ protocol. This protocol is based on the remaining energy of intermediate nodes to maintain the connectivity of the network as long as possible. The consequences obtained using the Network Simulator NS-2 demonstrates how little changes in the principle of the AODV protocol can competently balance the energy utilization among mobile devices of the network which increases the network lifetime as well as increases the throughput.
\end{abstract}

\section{KEYWORDS}

Ad hoc Network, AODV, MANET, Energy Efficiency

\section{INTRODUCTION}

Mobile ad hoc networks are collection of mobile nodes which can move without restraint and communicate with each other by means of a wireless physical medium. Consequently, dynamic topology, unbalanced links, restricted energy capacity and lack of fixed infrastructure are individual features for MANET when compared to wired networks. MANET does not have central controllers, which makes it different from conventional wireless networks [1]. MANETs, locate applications in several areas. A number of of them are: military applications, mutual and distributed computing, emergency operations, wireless mesh networks, wireless sensor network, and hybrid wireless network architectures. MANET routing protocols could be generally classified into two main categories based on the routing information update method. Proactive protocols constantly study the topology of the network by exchanging topological information among the network nodes. Therefore, when there is require for a path to a destination, such route information is available instantly. But the network topology changes too regularly, the cost of maintaining the network might be very high. If the network movement is small, the information about real topology might still not be used such as DSDV, WRP, CGSR, etc. The reactive routing protocols are based on a number of sort of query-reply dialog. Reactive protocols continue for establishing route to the destination only when the need arises. They do not require cyclic transmission of topological information of the network e.g. DSR, AODV, TORA, etc. Frequently reactive or proactive characteristic of a particular routing protocol might not be sufficient; as a substitute a mixture might yield better solution. Thus, in

DOI : $10.5121 / \mathrm{ijdps} .2012 .3603$ 
International Journal of Distributed and Parallel Systems (IJDPS) Vol.3, No.6, November 2012

the current days, a number of hybrid protocols are also proposed. In reactive protocols (also called "on-demand" routing approach) routing paths are discovered only on demand. A route discovery task invokes a route-determination procedure and which terminates when either a route is found or there is no possible route available. Because of nodes mobility, active routes may be disconnected and therefore route maintenance is important in reactive routing protocols. A reactive routing protocol has less control overhead as compared to the proactive routing protocol and therefore a reactive routing protocol has better scalability than a proactive routing protocol. However, source nodes may suffer from long delays for route discovery in reactive approach. Dynamic source routing and ad hoc on-demand distance vector routing are admired reactive routing protocols for MANET.

The individuality [2] of MANETs has led to intend of MANET definite routing protocols. These protocols are mostly classified as proactive and reactive. Proactive protocols are table driven i.e., nodes preserve information about the routes. Reactive routing protocol locate the routes only when they are needed i.e., on-demand. Reactive protocols have gained more significance as they decrease routing overhead and use less energy [4]. Energy is a limited resource in ad hoc wireless networks [3]. Every node has the functionality of substitute as a router along with being a source or destination. Therefore the breakdown of some nodes process can greatly slow down performance of the network and even influence the basic accessibility of the network, i.e., routing, accessibility, etc. Consequently it is of principal magnitude to use energy efficiently when establishing communication patterns. Energy organization is classified into battery power management, transmission power management and system power management. There are four energy cost metrics based on which we can make a decision the energy efficiency of a routing protocol. They are communication power, remaining energy capacity, estimated node lifetime and combined energy metrics. The totality of routing protocols, suggested by the Mobile Ad hoc Network group (MANET) of the Internet Engineering Task Force (IETF), use the same routing metric which is the shortest path. The paths are computed based on the minimization of the number of intermediate nodes between the source and the destination. Consequently, a number of nodes become dependable for outing packets from many source destination pairs. Later than a short period of time, the energy resources of those nodes get exhausted, which leads to node breakdown. It is consequently important that the routing protocols designed for ad hoc networks take into account this problem. Certainly, a better choice of routes is one wherever packets get routed through paths that may be longer but that include only nodes that have sufficient energy. Routing protocols in MANETs like AODV and DSR, usually intend to find a single path between a source and destination node. This paper aims at specifying an energy aware routing protocol based on this concept, and derives from the most known routing protocol: AODV (Ad-hoc on demand Distance Vector) and extension of AODV which is known as ECB-AODV. We show that this extension of ECB-AODV, called MECB-AODV (Modified Energy Constraint Based AODV), decrease the energy consumption by simply using energy aware routing metric.

The remaining part of the paper is organized as follows: In section 2 we will discuss the related works done in field of Energy Aware Routing in MANET and in section 3 we will discuss the comparison of energy constrained based routing protocols. In section 4 we will discuss the route discovery process of AODV routing protocol and in section 5 we will discuss the proposed approach. The simulation consequence will be discussed in section 6 and in section 7 we will conclude the paper and present the future scope of this paper.

\section{RELATED WORKS}

The exertion done in this background could be grouped into two main groups; the first describes methods for dropping energy consumption in the AODV protocol with diversifying the routing approach, and the second present's methods to decrease numbers of control messages in order to decrease the cost of consumption of energy. AODV is a reactive routing 
protocol as a substitute of proactive. It minimizes the amount of broadcasts by creating routes based on demand, which is not the case for DSDV. While any source node wants to send a packet to a destination, it broadcasts a route request (RREQ) packet. The neighboring nodes in turn broadcast the packet to their neighbors and the method continues until the packet reaches the destination. Throughout the process of forwarding the route request, intermediate nodes record the address of the neighbor from which the first copy of the broadcast packet is received. This record is stored in their route tables, which helps for establishing a reverse path. But supplementary copies of the same RREQ are later received, these packets are discarded. The reply is sent by the reverse path. In support of route maintenance, when a source node moves, it can reinitiate a route discovery process. If some intermediate node moves within a particular route, the neighbor of the drifted node can detect the link failure and sends a link failure warning to its upstream neighbor. This procedure continues until the crash notification reaches the source node. Based on the received information, the source might come to a decision to reinitiate the route discovery phase.

The propose work is aimed at developing energy efficient AODV routing protocol. This section documents some of the many energy efficient schemes based on AODV developed by researchers in the field. In [6], Jin-Man Kim and Jong-Wook Jang proposes an enhanced AODV (Ad-hoc On-demand Distance Vector) routing protocol which is modified to improve the networks lifetime in MANET (Mobile Ad-hoc Network). Individual enhancement for the AODV protocol is to maximize the networks lifetime by applying an Energy Mean Value algorithm which considerate node energy-aware. Enhance in the number of applications which use ad hoc network has led to enlarge in the development of algorithms which reflect on energy efficiency as the cost metric.

Yumei Liu, Lili Guo, Huizhu Ma and Tao Jiang [7] suggest a multipath routing protocol for mobile ad hoc networks, called MMRE-AOMDV, which extends the ad hoc on-demand multipath distance vector (AOMDV) routing protocol. The solution design of the protocol is to find the minimal nodal residual energy of each route in the process of selecting path and arrange multi-route by descending nodal residual energy. Formerly a new route with greater nodal residual energy is emerging; it is reselected to forward rest of the data packets. It can balance individual node's battery power consumption and hence prolong the entire network's lifetime. In [14] authors suggest a novel version of AODV called (MAODV) derived from the AODV routing protocol by allowing for the bit error rate (BER) at the end of a multi-hop path as the metric to be minimized for route selection. In [15], authors included the transmit power control and load balancing approach as a method to improve the performance of on-demand routing with energy efficiency. M.Veerayya, V. Sharma and A. Karandikar suggest in [16] a cross layering approach to switch information about the residual energy in nodes to perform quality of service. In [17] a new method is projected to set a timeout for a path. A path considered out of order if a node leave by following the exhaustion of its energy. In [18] authors combine the runtime battery capacity in routing protocol and the predictable real propagation power loss, obtained from sensing the received signal power. This result is independent of location information and using the broadcast, they approximate the energy loosed.

In [19] author suggests a different type of the planned work which aims to decrease the overhead of AODV to get energy efficiency. Authors suggest a new technique in order to reduce overhead in AODV in urban area by predicting links availability. By predicting neighbor nodes positions it can be determined probability of link failure. In [20] S.B. Kawish, B. Aslam, S. A. Khan studies the performance of AODV in a fixed networks and those exhibiting low mobility with a view to emphasize the reasons for reducing overhead and then reduce the energy consumption. The same authors present in [21] an improvement in their idea of using route timeout adjusted to reduce the overhead. In [22] Authors propose a new version of AODV an on-demand routing algorithm based on cross-layer power control termed as called 
CPC-AODV (Cross-layer Power Control Ad hoc On demand Distance Vector) taking account of the geographic location of nodes, the energy of packet transmission.

In [23] author suggest the approach which consists an algorithm that enables packet forwarding misbehavior and Loss Reduction based detection through the principle of conservation of flow on the routing protocol group nodes. First, unlikable the other proposed solution, our protocols, does not minimize the number of messages or the overhead, or use geographic coordinates of the nodes or the channel access using the MAC layer. Our solution simply changes the periodicity by random time for the receiver and set by the power level of the node battery the transmitter. This is a significant characteristic and has a reflective effect on energy consumption which could maintain the behavior of protocol. It is an available approach to incorporate routing protocols with power control in ad hoc networks.

In [8], Zhang Zhaoxiao, Pei Tingrui and Zeng Wenli propose a new mechanism of energyaware routing named EAODV, which is based on the classical AODV protocol. Here a backup routing mechanism is adopted. The route which spends a lesser amount of energy and owns larger capacity is selected by synthetic analysis. In [9], M. Phrika and Fatima Gaundhaur propose a new mechanism of energy constrained routing protocol based on AODV (ECBAODV) which is based on local decision of the nodes and uses the concept of saving the energy of nodes which have very less energy by using the concept of threshold energy. In on-demand ad hoc algorithms, all nodes participate in the phase of path searching, while the final decision is made in the source or destination node. The Woo et al. [24] algorithm grants each node in the network permission to decide whether to participate in route searching, which thus spreads the decision- making process among all nodes. The Local Energy-Aware Routing (LEAR) algorithm has as a main criterion the energy profile of the nodes. The residual energy defines the reluctance or willingness of intermediate nodes to respond to route requests and forward data traffic. When energy Ei in a node $\mathrm{i}$ is lower than a predefined threshold level Th:

\section{$\mathrm{Ei}<\mathrm{Th}$,}

The node does not forward the route request control message, but simply drops it. Thus, it does not participate in the selection and forwarding phase. The technique of shifting the responsibility for reacting to changes in the energy budget of the nodes from the sourcedestination nodes to the intermediate nodes avoids the need for the periodic exchange of control information. The Conditional MMBC algorithm in [25] is proposed to maximize the lifetime of the nodes. It also uses transmission energy as a metric but the route is chosen on the minimum transmission energy basis until the residual energy of the constituent nodes in a network is above a predefined threshold. If there are any nodes on the discovered routes whose energy is below the threshold, the MMBC is applied. The work done in [26] accounts not only for residual energy and transmission power but also for possible retransmissions. It brings an important aspect to light in the design of energy- efficient routing algorithms: the estimation of future energy consumption. The authors estimate the energy that is expected to be used in order to successfully send a packet across a given link. The cost metric as in Equation given below thus comprises a node-specific parameter (battery power Bi of node i) and a link-specific parameter (packet transmission energy $\mathrm{Ei}, \mathrm{j}$ ) for reliable communication across the link (between nodes $\mathrm{i}$ and $\mathrm{j}$ ):

$$
C_{i, j}=\frac{B_{i}}{E_{i, j}}
$$

Whereas the expected transmission energy as in Equation given below is defined by the power to transmit a packet over the link between nodes $\mathrm{i}$ and $\mathrm{j}(\mathrm{Ti}, \mathrm{j})$ and the link's packet error probability (pi,j): 


$$
E_{i, j}=\frac{T_{i, j}}{\left(1-P_{i, j}\right)^{L}}
$$

The main reason for adopting the above is that link characteristics can significantly affect energy consumption and can lead to excessive retransmissions of packets. The maximum lifetime of a given path is determined by the weakest intermediate node, which is that with the lowest cost. The approach is presented in [27] by Chiasserini and Rao, and subsequently by Ma and Yang [29]. Their solutions make use of the available battery capacity by means of batterysensitive routing. Both works study the lifetime of the battery and the algorithms proposed by their authors are based on two processes, namely, recovery (reimbursement) and discharging loss (over-consumed power). These processes are experienced when either no traffic or new traffic is transmitted. This line of study led to the design of a cost function that penalizes the discharging loss event and prioritizes routes with "well recovered" nodes. Thus, battery recovery can take place and a node's maximum battery capacity can be attained. The selection function is a minimum function over the cost functions of all routes. The routing algorithm used in this method is based on AODV. In AODVEA [5], routing is based on the metric of minimum remaining energy. The node with minimum remaining energy in the route is identified and the route having maximum of minimum remaining energy is selected.

The protocol performs a route discovery process similar to the AODV protocol. The difference is to determine an optimum route by considering the network lifetime and performance; that is, considering residual energy of nodes on the path and hop count. In order to implement such functions, a new field, called Min-RE field, is added to the RREQ message as described above. The Min-RE field is set to a default value of -1 when a source node broadcasts a new RREQ message for a route discovery process. Equation below gives the calculation of Routing metric for modified AODV:

$$
\alpha=\frac{(\operatorname{Min} R E)}{\text { Hop Count }}
$$

The optimum route is determined by using the value of $\alpha$ described above. The destination node calculates the values of $\alpha$ for received all route information and choose a route that has the largest value of $\alpha$. Here Min- RE is the minimum residual energy on the route and Hop Count is the hop count of the route between source and destination.

\section{COMPARISION OF EXISTING ENERGY CONSTRAINED ROUTING PROTOCOLS}

As per literature survey we have done survey on some of the parameters yet there are many parameter in the energy constrained based techniques which we can compare and put them in such a graph which will be helpful for the future researchers. There are various protocols are available in this area. We are doing a comparative study of main energy constrained based routing protocols, listed in tables based on characteristics and advantages and disadvantages. 
Table 1: Comparison of routing protocols

\begin{tabular}{|c|c|c|}
\hline $\begin{array}{lr}\text { Energy } & \text { constrained } \\
\text { based } & \text { routing } \\
\text { technique } & \\
\end{array}$ & Major characteristics & Route Discovery \\
\hline $\begin{array}{l}\text { Zone Based Routing } \\
\text { [10] }\end{array}$ & $\begin{array}{l}\text { - Use a fixed zone-based partition } \\
\text { scheme to partition the network. } \\
\text { - Usage of source based routing. } \\
\text { - ZBR has a good scalability. }\end{array}$ & $\begin{array}{l}\text { - Source based route } \\
\text { request. }\end{array}$ \\
\hline $\begin{array}{l}\text { Global Positioning } \\
\text { System [12] }\end{array}$ & $\begin{array}{l}\text { - GPS-free has been developed } \\
\text { that provides knowledge of the } \\
\text { geometric location of nodes in a } \\
\text { MANET }\end{array}$ & $\begin{array}{l}\text { - It uses optimization } \\
\text { technique for Route } \\
\text { Discovery. }\end{array}$ \\
\hline $\begin{array}{l}\text { Segment by segment } \\
\text { routing [11] }\end{array}$ & $\begin{array}{l}\text { - Region stability is defined as the } \\
\text { variance of nodes within a } \\
\text { region based on the neighbor } \\
\text { change ratio. }\end{array}$ & $\begin{array}{ll}\text { - } & \begin{array}{l}\text { Interregional } \\
\text { discovery. }\end{array} \\
\text { - } & \text { Intraregional } \\
& \text { route } \\
\text { discovery } & \end{array}$ \\
\hline $\begin{array}{lr}\text { Q-learning } & \text { ad-hoc on } \\
\text { demand } & \text { distance } \\
\text { vector } & \text { protocol } \\
(\text { QLAODV)[28] }\end{array}$ & $\begin{array}{l}\text { - Uses distributed Q-Learning to } \\
\text { infer network status } \\
\text { information. }\end{array}$ & $\begin{array}{l}\text { It use discount factor } \\
\text { for RREQ. }\end{array}$ \\
\hline $\begin{array}{lr}\begin{array}{l}\text { Multicast } \\
\text { demand }\end{array} & \text { distance } \\
\text { vector } & \text { protocol } \\
(\text { MAODV) } & 14]\end{array}$ & $\begin{array}{l}\text { It is loop free. It uses distributed } \\
\text { operation. }\end{array}$ & $\begin{array}{l}\text { - } \\
\text { Source } \\
\text { multicast } \\
\text { packet. }\end{array}$ \\
\hline
\end{tabular}

\begin{tabular}{|c|c|c|}
\hline $\begin{array}{l}\text { Energy constrained } \\
\text { based routing technique }\end{array}$ & ADVANTAGES & DISADVANTAGES \\
\hline Zone Based Routing [10] & $\begin{array}{l}\text { - lower overhead, } \\
\text { - lower probability of link } \\
\text { breakage } \\
\text { - higher throughput }\end{array}$ & 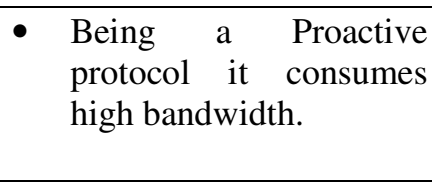 \\
\hline $\begin{array}{l}\text { Segment by segment [11] } \\
\text { routing }\end{array}$ & $\begin{array}{l}\text { - It has scalability compare to } \\
\text { GPSR. } \\
\text { - It has higher packet delivery } \\
\text { ratio when compared with } \\
\text { GPSR. }\end{array}$ & $\begin{array}{l}\text { - Control complexity is } \\
\text { higher than GPSR. }\end{array}$ \\
\hline $\begin{array}{l}\text { Q-learning ad-hoc on } \\
\text { demand distance vector } \\
\text { protocol (QLAODV) [28] }\end{array}$ & $\begin{array}{l}\text { Bandwidth } \text { Efficient, } \\
\text { QLAODV can efficiently } \\
\text { reduce the number of route } \\
\text { errors and route discoveries }\end{array}$ & $\begin{array}{l}\text { Packet loss ratio is } \\
\text { higher than MAODV. }\end{array}$ \\
\hline
\end{tabular}


International Journal of Distributed and Parallel Systems (IJDPS) Vol.3, No.6, November 2012

\begin{tabular}{|l|ll|ll|}
\hline $\begin{array}{l}\text { Multicast Ad-hoc on } \\
\text { demand distance vector } \\
\text { protocol (MAODV) [14] }\end{array}$ & $\bullet \begin{array}{l}\text { Data forwarding overhead is } \\
\text { low. }\end{array}$ & $\begin{array}{l}\bullet \\
\bullet\end{array}$ & $\begin{array}{l}\text { It induces great traffic. } \\
\text { Its scalability is poor. } \\
\text { Group Leader is Single } \\
\text { Point of Failure. }\end{array}$ \\
\hline $\begin{array}{l}\text { Long Lived Route } \\
\text { Prediction[13] }\end{array}$ & $\begin{array}{l}\bullet \begin{array}{l}\text { This will not be affected by } \\
\text { the presence of shadow } \\
\text { effect. }\end{array} \\
\begin{array}{l}\text { Energy constrained based } \\
\text { routing protocol based on } \\
\text { AODV( ECB-AODV)[9] }\end{array}\end{array}$ & $\bullet \begin{array}{l}\text { Increase network life time. } \\
\text { area. }\end{array}$ & $\bullet \begin{array}{l}\text { Less resource } \\
\text { utilization. }\end{array}$ \\
\hline
\end{tabular}

Here in this paper we are proposing the concept of maximum energy in AODV that the neighbors that have maximum energy only they will receive the HELLO message.

\section{AODV ROUTING PROTOCOL}

The AODV protocol is a reactive unicast routing approach for mobile ad hoc networks and therefore AODV only has to maintain the routing information about the active routes. Routing information in AODV is maintained in routing tables at nodes. Every node maintains a nexthop routing table that has the destinations to which it has an active route. A routing table entry drop dead if not used or reactivated for a predefined expiration time. Additionally, AODV assumes the destination sequence number mechanism as used in DSDV but in an on-demand way.

In AODV, in absence of available route, a source node initiates a route discovery procedure before sending a packet. The route discovery phase involves broadcasting of route request (RREQ) packets which contain source and destination addresses, broadcast ID, which acts as its identifier, the last visited destination's sequence number as well as the source node's sequence number.

Sequence numbers ensures loop-free and up-to-date paths. Flooding overhead in AODV is reduced by a node discarding RREQs by a node if it has seen before and the route discovery operation is done by expanding ring search algorithm. The RREQ initiates with a small TimeTo-Live (TTL) value which is increased in the next RREQ if destination is not found.

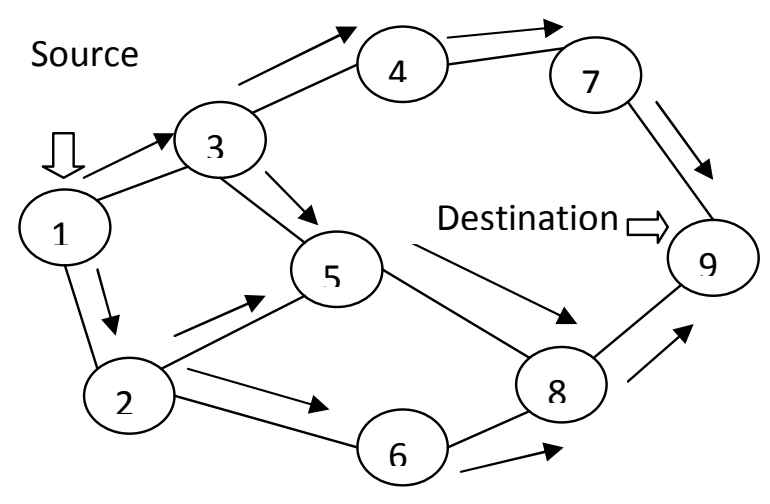

Fig.1:The Route Request Packets Flooding in AODV 


\section{PROPOSED ROUTING PROTOCOL}

When a source node wants to reach a destination node, it starts the route discovery process and broadcasts the route request packets (RREQ), as in AODV. But when an intermediate node receives this request, there is an additional step that it has to do before sending the packet: it must compare its remaining energy with a certain threshold. If it finds that its energy level exceeds the threshold value, it rebroadcasts the request to all its neighbors. In the other case, the node concludes that its remaining energy is not enough anymore to route the others' packets. Therefore, the node rejects the RREQ packets and ignores the request.

As soon as the destination receives the first RREQ packet, it transmits a RREP towards the source. The treatment of these RREP packets by the source is identical to that of AODV.

But we have modified this scenario by using the concept of remaining maximum energy of nodes. When a source node wants to communicate with destination then in route discovery process the route request packet will be sent to that node which has maximum remaining energy so that the path found will have that maximum energy and can survive for a longer time.

\subsection{ALGORITHM}

Here we can describe the algorithm based on Energy Constrained Based Routing protocols. In this we proposed an algorithm which is based on maximum remaining energy of node. The algorithm explained as below;

\begin{tabular}{|l|l|}
\hline & Begin \\
\hline Step1. & Initialize network (Source, Destination) \\
\hline Step2. & Find neighbors of source node \\
\hline Step3. & Select the node which has maximum remaining energy \\
\hline $\mathbf{3 ( a )}$ & Send the packet to the neighbor node \\
\hline Step4. & NEXTHOP $\boldsymbol{k}: \boldsymbol{e}_{\boldsymbol{k}}^{\text {remain }}=\boldsymbol{m a x}\left\{\boldsymbol{e}_{j}^{\text {remain }}\right\}$ \\
\hline Step5. & If all the neighbors have same energy \\
\hline & $\begin{array}{l}\text { All neighbors have to find their neighbors and tell the maximum remaining energy of } \\
\text { next neighbor's node. }\end{array}$ \\
\hline Step6. & Else follow step3 and 4. \\
\hline Step7. & Repeat Step2-5 until request is reached at the destination. \\
\hline Step8. & Reply via same path on which request is reached. \\
\hline & End. \\
\hline
\end{tabular}

We will compare our modified model with existing AODV model and show that our model will gives better result in terms of network lifetime, energy consumption as well as signaling overhead will be shown via simulation but we will show with example that our model has longer network lifetime.

Example: Here we show that the example of our model in which we choose the next hop which have maximum remaining energy.

Table2: Energy table of all nodes
\begin{tabular}{|c|c|}
\hline Node & $\begin{array}{l}\text { Minimum Residual } \\
\text { Energy (Joule) }\end{array}$ \\
\hline S & 500 \\
\hline 1 & 400 \\
\hline 2 & 300 \\
\hline 3 & 700 \\
\hline 4 & 500 \\
\hline
\end{tabular}


International Journal of Distributed and Parallel Systems (IJDPS) Vol.3, No.6, November 2012

\begin{tabular}{|c|c|}
\hline 5 & 400 \\
\hline 6 & 300 \\
\hline 7 & 600 \\
\hline 8 & 500 \\
\hline 9 & 400 \\
\hline 10 & 200 \\
\hline$D$ & 500 \\
\hline
\end{tabular}

Steps of Route request: Following steps explained the route request in MECB-AODV;

\section{Step 1}

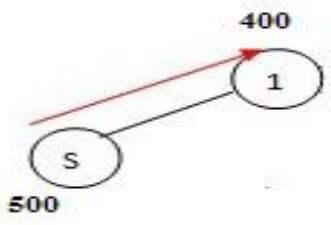

Step 2

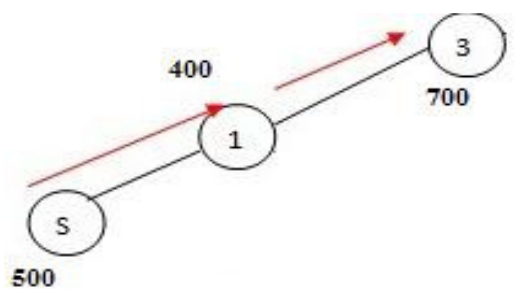

Step 3

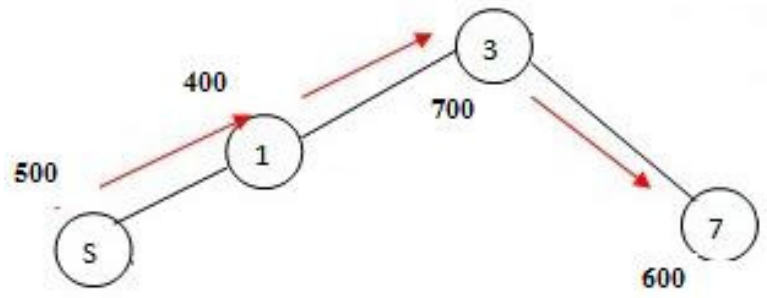

Step 4

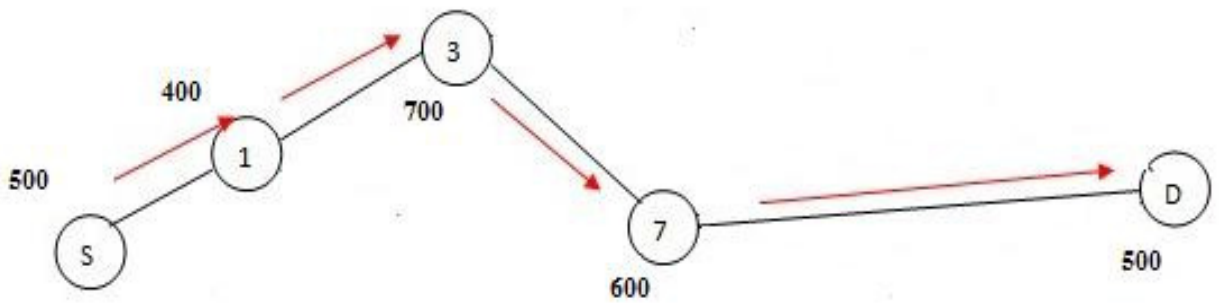


International Journal of Distributed and Parallel Systems (IJDPS) Vol.3, No.6, November 2012

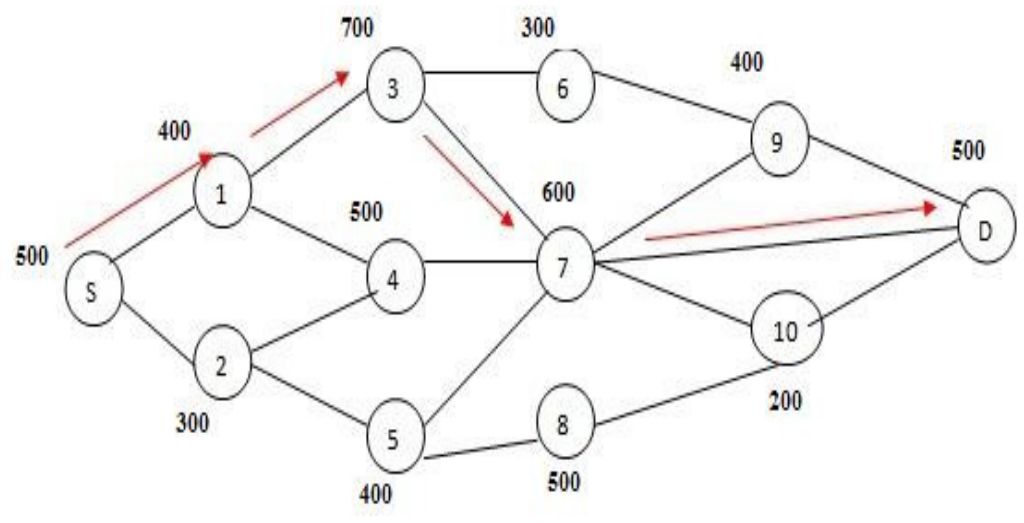

Figure 2(a): Route Request in MECB-AODV

Route reply step: following steps explained the route reply in MECB-AODV;

Step 1

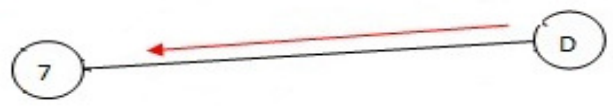

Step 2

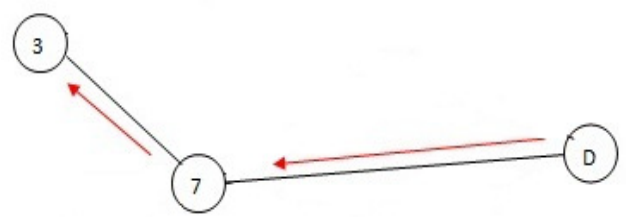

Step 3

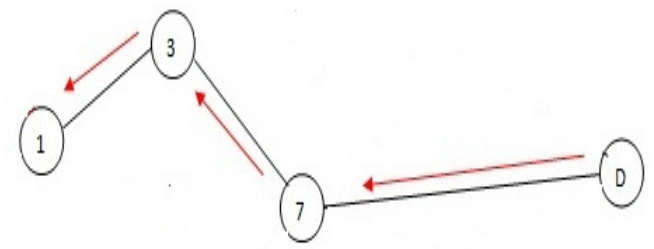




\section{Step 4}
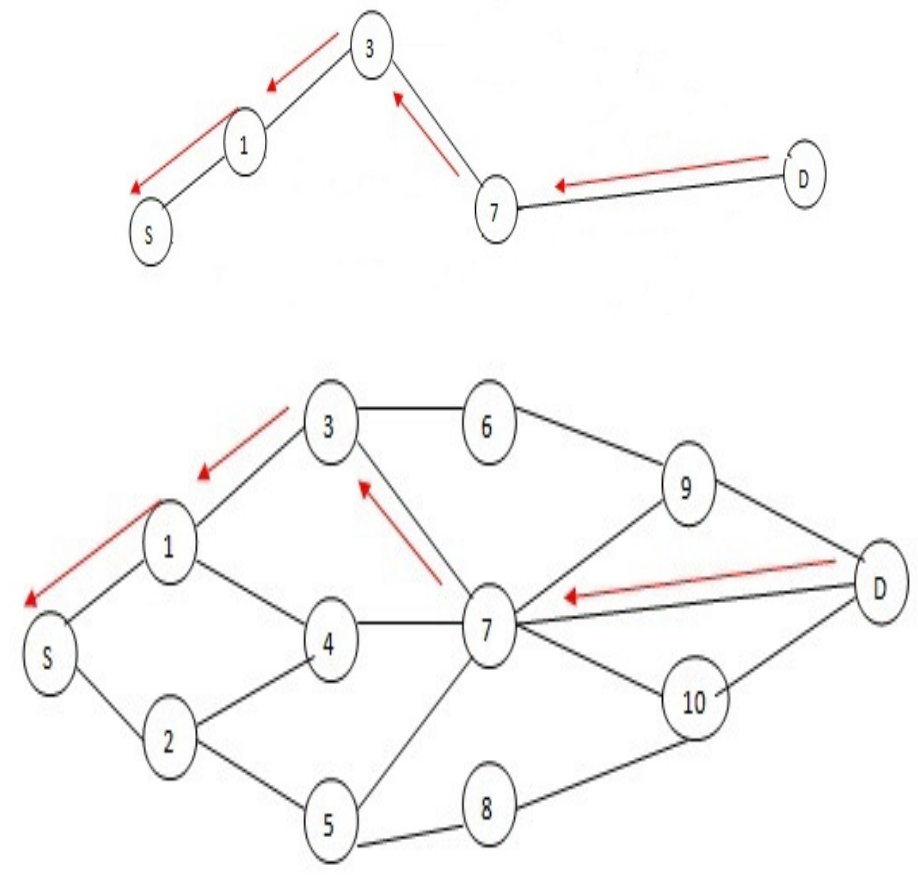

Figure 2(b): Route Reply in MECB-AODV

\section{PERFORMANCE EVALUATION}

We have created several simulation scenarios with NS-2 to evaluate MECB-AODV protocol. The topology have used in our experiments is that shown in figure 3 . The total band-width considered is $2 \mathrm{Mbps}$ and the radio range of each node is 250 meters. A first TCP connection is established between nodes $\mathrm{S}$ and $\mathrm{D}$ after 10 seconds from the beginning of the simulation, which lasted 40 seconds. At $\mathrm{t}=18$ seconds, we want to set up a new communication that connects node- 5 to node- 9 . The results are shown in figure 4 . We first look at the energy consumption of the network, when using the original routing protocols, AODV. The same experiment carried out with MECB-AODV leads to a very different result.

We used Network Simulator 2 (NS2) to evaluate the performance of MECB-AODV. To compare MECB-AODV with prior work in routing AODV, this uses flooding. In our simulation, the time intervals of the beacons and the global location updates were chosen to be $1 \mathrm{~s}$ and $8 \mathrm{~s}$, respectively. We simulated 6 CBR traffic flows, originating from randomly-selected sending nodes. Each CBR flow sends at $1 \mathrm{Kbps}$, and uses 64 -byte packets. Each simulation lasts for 40 seconds of simulated time. The following aspects of MECB-AODV are emphasized:

- Adaptation with changes in the network topology.

- Signaling overhead.

- Energy Consumed.

- Packet Delivery Ratio. 
Table3: Simulation Parameters

\begin{tabular}{|c|c|}
\hline Matrices & Dimension \\
\hline Area & $1500^{*} 1500$ \\
\hline No. of Nodes & 21 \\
\hline $\begin{array}{l}\text { Minimum } \\
\text { Transmission Power }\end{array}$ & $3.97 \mathrm{e}-6 \mathrm{~mW}$ \\
\hline Data Rate & $1 \mathrm{kbps}$ \\
\hline Simulation Time & $40 \mathrm{Sec}$ \\
\hline Pause time (QTR) & $15 \mathrm{Sec}$ \\
\hline Periodic update & $1-8 \mathrm{sec}$ \\
\hline MAC Layer & IEEE 802.11 \\
\hline Bandwidth & $2 \mathrm{Mbps}$ \\
\hline Radio Range & $250 \mathrm{~m}$ \\
\hline Initial Energy & \\
\hline
\end{tabular}

- Signaling Overhead

In order to find the best available route, protocol MECB-AODV needs to propagate more control packets in the network during the process of route discovery. This signaling overhead can be measured, for each simulation, by the following formula:

Signaling overhead $=$ (total number of control Packets $) /$ (total number of data packets $)$.

- Packet Delivery Ratio:

It can be defined as the percentage of ratio between the number of packets received at the destination and the number of packets sent by source.

Packet delivery ratio $=\sum_{\mathrm{i}}$ (No. of received packet at destination ${ }_{\mathrm{i}} /$ No. of packet sent by source $\left._{\mathrm{i}}\right)^{*} 100$

- Energy Consumption:

The energy consumed when nodes are forwarding a packet is equal to the sum of transmitting and receiving the packet,

$$
\mathrm{Et}=\mathrm{Etx}+\mathrm{Erx}
$$

Where

Etx is energy consumed in transmission of packet

Erx is energy consumed in receiving the packet 
International Journal of Distributed and Parallel Systems (IJDPS) Vol.3, No.6, November 2012

Etx $=$ Ptx $\times 8 \times$ Packet size /Bandwidth

Erx $=$ Prx x 8 x Packet size /Bandwidth

Where

Ptx is transmission power

Prx is receiving power

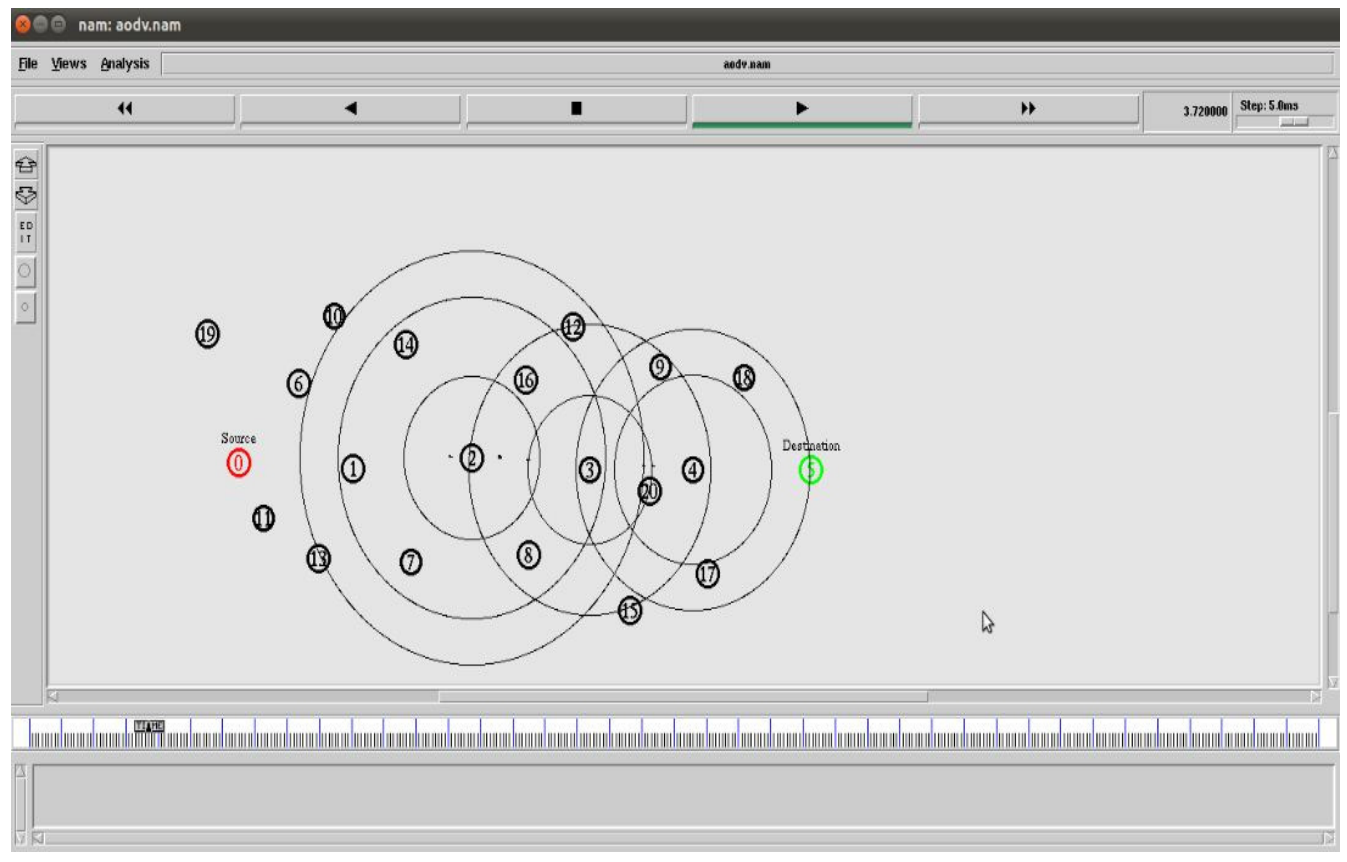

Figure 3: Network Topology

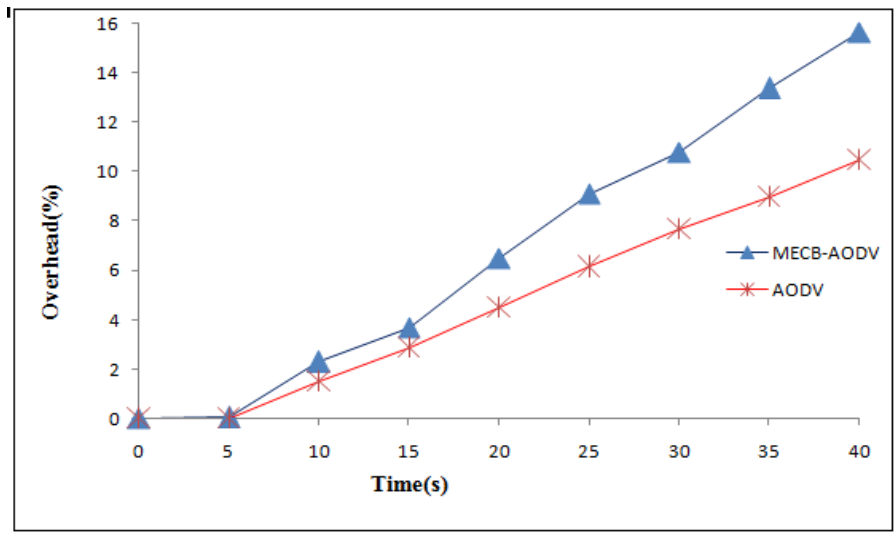

Figure 4 (a): Overhead Vs Time 
The number of packets originated by the source at application layer to number of packets received by the destination node, which also known as the packet delivery ratio. Figure 4 (b) shows that the delivery ratio in which result is shown between packet ratio and Time.

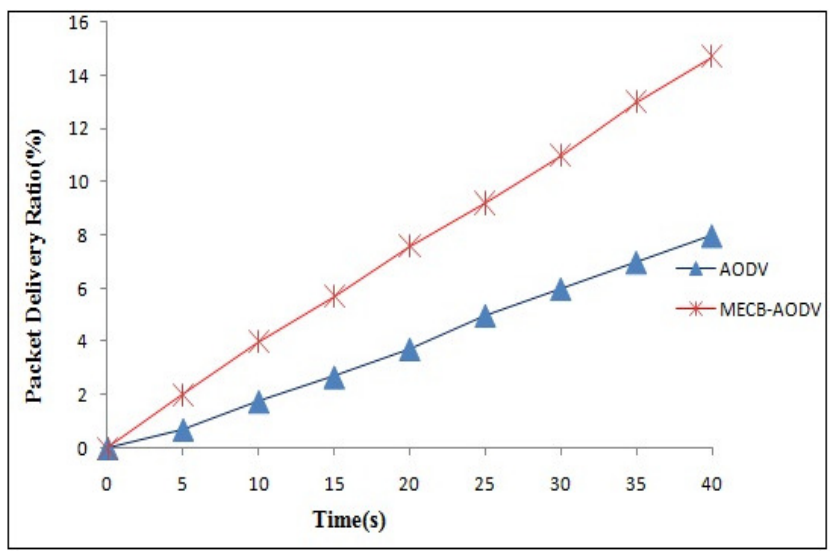

Figure 4 (b): Packet Delivery Ratio

The next result shows energy consumed by AODV as well as MECB-AODV in which it shows that our proposed protocol performs better than AODV. The energy consumed in AODV is higher than MECB-AODV.

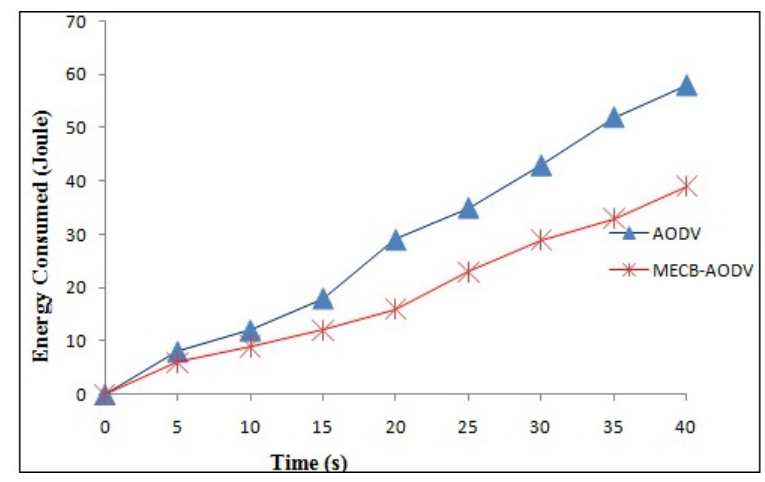

Figure 4 (c): Energy Consumed Vs Time

\section{CONCLUSION AND FUTURE SCOPE}

This paper provides an overview of MANETs and discusses how energy is one of the most important constraints for these types of networks. The objective of the proposed work is to develop an energy efficient AODV routing algorithm in a way which allows researchers to choose the most appropriate routing algorithm. We have also simulated our work by using network simulator and result shows that our proposed model always performs better than AODV. We can also extend this work proposing more efficient methods as well as can be implemented this work on sensor network. As a global conclusion we could also state that current energy constrained protocols may need some tuning to minimize the power cost of network interface. As we saw, the cost of energy consumption in sending packets can be significant to the cost of being idle, but application and transport level considerations can make the idle cost the dominant cost. Several protocols that put down a mobile receiver idle without need wastes power. 
International Journal of Distributed and Parallel Systems (IJDPS) Vol.3, No.6, November 2012

\section{REFERENCES}

[1]. Lijuan Cao, Teresa Dahlberg and Yu Wang, "Performance Evaluation of Energy Efficient Ad Hoc Routing Protocols", IEEE 2007.

[2]. C. Siva Ram Murthy, B. S. Manoj, "Ad Hoc Wireless Networks Architecture and Protocols", 2nd ed, Pearson Education, 2005.

[3]. Ioanis Nikolaidis, Michel Barbeau, Evangelos Kranakis, "Ad-Hoc, Mobile, and Wireless Networks", Third International Conference, ADHOC_NOW 2004.

[4]. M. Pushpalatha, Revathi Venkataraman, and T. Ramarao, "Trust Based Energy Aware Reliable Reactive Protocol in Mobile Ad Hoc Networks", World Academy of Science, Engineering and Technology 2009.

[5]. G.Vijaya Kumar, Y.Vasudeva Reddyr and Dr.M.Nagendra, "Current Research Work on Routing Protocols for MANET: A Literature Survey", (IJCSE) International Journal on Computer Science and Engineering 2010.

[6]. Jin-Man Kim, Jong-Wook Jang, "AODV based Energy Efficient Routing Protocol for Maximum Lifetime in MANET”, IEEE 2006.

[7]. Liu, Lili Guo,Huizhu Ma,Tao Jiang, "Energy Efficient on-demand Multipath Routing Protocol for Multi-hop Ad Hoc Networks”, IEEE 2008.

[ 8]. Zhang Zhaoxiao, Pei Tingrui, Zeng Wenli, "Modified Energy-Aware AODV Routing for Ad hoc Networks", IEEE 2009.

[ 9]. M Frikha and Fatma ghandaour, "Implementation And Performance Evaluation Of An Energy Constraint Routing Protocol For Mobile Ad Hoc Networks", AICT,07, IEEE.

[ 10]. Jieying Zhou, Simeng Wang, Hongda Feng , “ZBMRP: A Zone Based Multicast Routing Protocol for Mobile Ad Hoc Networks," First International Conference, MSN 2005, Wuhan, China, December 13-15, 2005

[11]. H. B. Li, Y. B. Cai, and Z. C. Li, "A Method of Selecting Steady Path Based on Neighbor Change Ratio in Mobile Ad Hoc Networks," Journal of Software, 2007, Vol. 18, No. 3, pp. 681692

[12]. Mehran Abolhasan and Tadeusz Wysocki, "GPS-based Route Discovery Algorithms for Ondemand Routing Protocols in MANETs," Telecommunication and Information Research Institute, University of Wollongong, NSW 2522, Australia.

[13]. Chun-Yen Hsu*, Jean-Lien C. Wu," Finding Stable Routes in Mobile Ad Hoc Networks", 07695-2051-0/04 \$20.00 @ 2004 IEEE

[14]. G. Ferrari, S. A. Malvassori, M. Bragalini, O. K. Tonguz, Physical Layer-Constrained Routing in Ad-hoc Wireless Networks: A Modi_ed AODV Protocol with Power Control, IWWAN, 2005 .

[15]. M. Tamilarasi, T.G. Palanivelu, Integrated Energy-Aware Mechanism for MANETs using On demand Routing , International Journal of Computer and Information Engineering,2008

[16]. M. Veerayya, V. Sharma, A. Karandikar, SQ-AODV: A novel energy aware stability based routing protocol for enhanced QOS in wireless ad-hoc networks, MILCOM 2008.

[17]. M. Tamilarasi, T.G. Palanivelu, Adaptive link timeout with energy aware mechanism for on demand routing in MANETs, Ubiquitous Computing and Communication Journal, 2010. 
International Journal of Distributed and Parallel Systems (IJDPS) Vol.3, No.6, November 2012

[18]. R.C.Shah,J.M. Rabaey, Energy aware routing for low energy ad hoc sensor networks, WCN, 2002.

[ 19]. R. Ghanbarzadeh, M. R. Meybodi, Reducing message overhead of AODV routing protocol in urban area by using link availability prediction, Second International Conference on Computer Research and Development, 2010.

[20]. S.B. Kawish, B. Aslam, S. A. Khan, Reducing the Overhead Cost in Fixed and Low Mobility AODV Based MANETs, Proceedings of the International Multiconference on Computer Science and Information Technology, 2006.

[21]. S.B. Kawish, B. Aslam, S. A. Khan, Reduction of Overheads with Dynamic Caching in Fixed AODV based MANETs, World Academy of Science, Engineering and Technology,2006.

[ 22]. H. Huang, G. Hu, F. Yu, A Routing Algorithm Based on Cross-layer Power Control in Wireless Ad Hoc Networks, Communications and Networking in China (CHINACOM), 2010

[23]. K.T. Sikamani, P.K. Kumaresan, M. Kannan, R. Madhusudhanan, Simple Packet Forwarding and Loss Reduction for Improving Energy Efficient Routing Protocols in Mobile Ad-Hoc Networks, European Journal of Scientific Research, 2009.

[24]. S. Yin, X. Lin, "Multipath minimum energy routing in ad hoc network", Proc. Int. Conf.Communications (ICC), IEEE, 2005, pp. 3182-3186.

[25]. C.-K. Toh, H. Cobb, D.A. Scott, "Performance evaluation of battery-life-aware routing schemes for wireless ad hoc networks", Proc. ICC, IEEE, 2001.

[26]. Vivek Kumar, "Simulation and Comparison of AODV and DSR Routing Protocols in MANETs" Master's Thesis, Thapar University(TU), 2009.

[27]. C.-F. Chiasserini and R.R. Rao, "Routing protocols to maximize battery efficiency", in Proc.MILCOM, IEEE, 2000.

[28]. Kavita Taneja1 and R. B. Patel2," Mobile Ad hoc Networks: Challenges and Future", Proceedings of National Conference on Challenges \& Opportunities in Information Technology (COIT-2007) RIMT-IET, Mandi Gobindgarh. March 23, 2007.

[29]. X. Zheng, W. Guo, R. Liu, Y. Tian, "A new dynamic oad-aware based load-balanced routing for adhoc networks”, Proc. ICCCAS, IEEE, 2004. 